\title{
Thermic Effect of Food in Lean and Obese Men
}

\author{
D. A. D'Alessio, E. C. Kavle, M. A. Mozzoli, K. J. Smalley, M. Polansky, Z. V. Kendrick, L. R. Owen, \\ M. C. Bushman, G. Boden, and O. E. Owen \\ Department of Medicine and the General Clinical Research Center, Temple University School of Medicine, Philadelphia, Pennsylvania \\ 19140; and the Department of Statistics and the College of Health, Physical Education, Recreation, and Dance, \\ Temple University, Philadelphia, Pennsylvania 19122
}

\begin{abstract}
A systematic reappraisal of the thermic effect of food was done in lean and obese males randomly fed mixed meals containing $0,8,16,24$, and $32 \mathrm{kcal} / \mathrm{kg}$ fat-free mass. Densitometric analysis was used to measure body composition. Preprandial and postprandial energy expenditures were measured by indirect calorimetry.

The data show that the thermic effect of food was linearly correlated with caloric intake, and that the magnitude and duration of augmented postprandial thermogenesis increased linearly with caloric consumption. Postprandial energy expenditures over resting metabolic requirements were indistinguishable when comparing lean and obese men for a given caloric intake. Individuals, however, had distinct and consistent thermic responses to progressively greater caloric challenges. These unique thermic profiles to food ingestion were also independent of leanness or obesity.

We conclude that the thermic effect of food increases linearly with caloric intake, and is independent of leanness and obesity.
\end{abstract}

\section{Introduction}

By current estimates, one in five citizens in the U. S. A. is overweight (1). The association of obesity with a variety of disease states, especially cardiovascular diseases (2-4) and diabetes mellitus $(1,5)$, has added impetus to efforts to understand the etiological factors of this condition. Although energy balance has been well studied, the development of conclusive explanations for the genesis and maintenance of obesity has remained elusive.

There are several physiologic states which are known to influence energy expenditure. The postprandial rise in caloric expenditure and its relationship to obesity have been the subject of intensive studies in the last decade. Numerous studies have shown that the thermic effect of food (TEF) ${ }^{1}$ is blunted in

Address all correspondence to Dr. Oliver E. Owen, General Clinical Research Center, Temple University Health Sciences Center, Broad and Ontario Streets, Philadelphia, PA 19140.

Received for publication 18 May 1987 and in revised form $18 \mathrm{De}$ cember 1987.

1. Abbreviations used in this paper: BMI, body mass index; $\mathrm{CHO}$, carbohydrate; EE, energy expenditure; FAT, lipid; HT, height; PRO, protein; RMR, resting metabolic requirements; TEF, thermic effect of food; WT, weight.

J. Clin. Invest.

(c) The American Society for Clinical Investigation, Inc.

0021-9738/88/06/1781/09 $\$ 2.00$

Volume 81, June 1988, 1781-1789 obese subjects (6-20). The authors of these reports claimed that because fewer nutrients were oxidized by obese humans, relatively more nutrients were stored by obese than lean people per caloric intake. They considered obese individuals to be metabolically more efficient than lean people during the postprandial period, thus promoting obesity. Others, however, found no defect of TEF in obese humans (21-32). Table I summarizes these conflicting studies. Overall, the discrepancies between these two groups of studies cannot be explained by differences in the amounts or compositions of caloric challenges given, the duration of the studies, or the definitions of TEF. The lack of consensus among investigators has not been resolved.

A factor that has not been consistently considered in previous studies of TEF in obesity is the influence of the resting metabolic requirements (RMR) on TEF. A given quantity of nutrients may augment the increase in energy expenditure less in heavy persons because their RMR are greater. Therefore, comparing obese subjects with lean controls, using equal caloric challenges, may give the false impression that the TEF is less in the obese.

Because of this controversy in such an important domain of postprandial metabolism, we believed that a systematic reappraisal of TEF in lean and obese humans was needed. We fed normal lean and obese male volunteers a series of mixed meals, with the caloric content based upon multiples of their fat-free mass. This allowed us to account for differences in their RMR and gave us the opportunity to study thermogenesis in response to varying caloric intakes.

\section{Methods}

Subjects. Five lean and five obese men were admitted to the General Clinical Research Center at Temple University Hospital for the $5 \mathrm{~d}$ inpatient study. The volunteers were informed of the study protocol and purpose, and they gave written consent; the study was approved by the Temple University Hospital Investigational Review Board. The volunteers were in good health and free of any chronic medical illness. Their physical and biochemical measurements are shown in Table II. Both groups were comparably young. All had normal hemograms, fasting plasma glucose concentrations, and thyroid, renal, and liver functions. They had been eating balanced meals and had maintained stable weights in the month before being studied. Their principal activities were approximately comparable from day to day. Professional and/or world-class athletes were excluded.

The volunteers were weighed underwater for densitometric analysis of body composition: fat-free mass and fat mass (33). Body mass indexes (BMI) were calculated using admission weights (WT) and heights (HT) (34).

Experimental design. Patients were admitted to the General Clinical Research Center the night before starting the indirect calorimetry studies. They were fed balanced meals with adequate calories and were familiarized with the indirect calorimetry equipment. After an overnight 11-12-h fast, the subjects voided urine and had an antecubital vein cannulated for blood sampling; this line was maintained patent with minimal infusions of saline. They remained resting in bed for $\mathbf{3 0}$ 
Table I. Compilation of Studies Comparing Thermic Effect of Food in Lean and Obese Subjects*

\begin{tabular}{|c|c|c|c|}
\hline Reference no. & Quantity and nature of caloric challenge & Duration of study & Definition of TEF \\
\hline \multicolumn{4}{|c|}{ Thermic defect in obese subjects } \\
\hline 6. & $200 \mathrm{kcal}$, oral glucose & $2.5 \mathrm{~h}$ & \% of RMR \\
\hline 7. & $850 \mathrm{kcal}$, oral CHO/PRO & $5 \mathrm{~h}$ & Increase in $\mathrm{VO}_{2}$ over baseline \\
\hline 8. & $9.8 \mathrm{kcal} / \mathrm{kg}$ ideal body wt, mixed & $2 \mathrm{~h}$ & Increase in EE over RMR \\
\hline 9. & 2,390 and $1,195 \mathrm{kcal} / \mathrm{d}$, mixed with fat supplement & $24 \mathrm{~h}$ & Increase in EE over RMR \\
\hline 10. & $400 \mathrm{kcăl}$, oral glucose & $3 \mathbf{h}$ & \% of RMR \\
\hline 11. & $400 \mathrm{kcal}$, fat & $1.5 \mathrm{~h}$ & $\begin{array}{l}\text { Increase in } \mathrm{VO}_{2} \text { over baseline } \\
\% \text { of caloric intake }\end{array}$ \\
\hline 12. & $800 \mathrm{kcal}$, mixed & $2 \mathrm{~h}$ & Increase in EE over RMR \\
\hline 13. & $60 \% 24$ h RMR, mixed & $5 \mathrm{~h}$ & $\begin{array}{l}\% \text { of RMR } \\
\% \text { of caloric intake }\end{array}$ \\
\hline 14. & $41.2 \mathrm{kcal} / \mathrm{kg}$ FFM, mixed & $24 \mathrm{~h}$ & $\begin{array}{l}\% \text { of RMR } \\
\% \text { of caloric intake }\end{array}$ \\
\hline 15. & $20 \%$ intravenous glucose infusion & $30 \mathrm{~min}$ & $\%$ of RMR \\
\hline 16. & 910 kcal, mixed & $20 \mathrm{~min}$ & Increase in $\mathrm{VO}_{2}$ over baseline \\
\hline 17. & $400 \mathrm{kccal}$, oral glucose & $3 \mathbf{h}$ & $\begin{array}{l}\text { \% RMR } \\
\text { \% caloric intake }\end{array}$ \\
\hline 18. & Intravenous glucose and insulin & $40 \mathrm{~min}$ & Increase in EE over RMR \\
\hline 19. & $750 \mathrm{kcal}$, mixed & $3 \mathrm{~h}$ & Increase in $\mathrm{VO}_{2}$ over baseline \\
\hline 20. & $750 \mathrm{kcal}$, mixed & $3 \mathbf{h}$ & Increase in $\mathrm{VO}_{2}$ over baseline \\
\hline \multicolumn{4}{|c|}{ No thermic defect in obese subjects } \\
\hline 21. & $100 \mathrm{~g}$, oral glucose & $3 \mathbf{h}$ & Change in glucose oxidation and storage \\
\hline 22. & $5 \mathrm{~g} / \mathrm{kg}$ ideal body wt, glucose and sucrose & $3 \mathbf{h}$ & Increase in EE over RMR \\
\hline 23. & $400 \mathrm{kcal}$, oral dextrose & $3 \mathbf{h}$ & Increase in EE over RMR \\
\hline 24. & $300 \mathrm{kcal}$, fat, PRO, or glucose & $2.5 \mathrm{~h}$ & $\begin{array}{l}\text { Increase in EE over RMR } \\
\text { \% of RMR }\end{array}$ \\
\hline 25. & $1,050 \mathrm{kcal}$, mixed & $24 \mathrm{~h}$ & Increase over control \\
\hline 26. & $800 \mathrm{kcal}$, mixed & $3 \mathbf{h}$ & Increase in EE over RMR \\
\hline 27. & $\begin{array}{c}800 \mathrm{kcal} \text {, high CHO } \\
\text { high fat }\end{array}$ & $6 \mathrm{~h}$ & $\begin{array}{l}\text { Increase in EE over RMR } \\
\text { \% caloric intake }\end{array}$ \\
\hline 28. & Intravenous glucose and insulin & $30 \mathrm{~min}$ & Change in glucose oxidation and storage \\
\hline 29. & $\begin{array}{l}400 \mathrm{kcal} \text {, fat, PRO, or glucose } \\
400 \mathrm{kcal} \text {, mixed }\end{array}$ & $1.5 \mathrm{~h}$ & $\begin{array}{l}\text { \% RMR } \\
\text { Mean EE } \\
\text { Increase in EE over fasting }\end{array}$ \\
\hline 30. & $11 \mathrm{kcal} / \mathrm{kg}$, mixed & $4-6 h$ & Increase in EE over RMR \\
\hline 31. & $300 \mathrm{kcal}$, oral glucose & $2.5 \mathrm{~h}$ & Increase in EE over RMR \\
\hline 32. & $\begin{array}{l}\text { Twice } 3 \text { h RMR, mixed } \\
\text { intravenous or nasogastric tube }\end{array}$ & $\begin{array}{l}3 \mathrm{~h} \text { infusion } \\
3 \mathrm{~h} \text { after infusion }\end{array}$ & $\begin{array}{l}\text { \% RMR } \\
\text { \% caloric intake }\end{array}$ \\
\hline
\end{tabular}

EE, energy expenditure; FFM, fat-free mass. * Modified from the presentation of E. Ravussin at the Joint Conference on Obesity and NIDDM, Toronto 1985.

min before initiating the indirect calorimetric measurements and throughout the 8-h postprandial period. The studies were done in a quiet room where the temperature was $22-24^{\circ} \mathrm{C}$.

After determination of the RMR, subjects drank $500 \mathrm{ml}$ of water or mixed liquid meals (Ensure Plus: 53\% carbohydrate, 32\% fat, 15\% protein, Ross Laboratories, Columbus, $\mathrm{OH}$ ) with volumes adjusted to provide $8,16,24$, or $32 \mathrm{kcal} / \mathrm{kg}$ fat-free mass. The five different intakes over the 5-d study periods were randomized by the Latin Squares technique (35). The volunteers consumed the mixed liquid meals during a 10 -min period, and then returned to a supine resting position for further blood sampling and measuring of respiratory gases for the next $8 \mathrm{~h}$.
Measurements of $\mathrm{O}_{2}$ consumption and $\mathrm{CO}_{2}$ production were obtained at -15 and 0 min before feeding, every 15 min during the $1 \mathrm{st}$ postprandial hour and every 30 min during the next 7 postprandial hours. Measurements of $\mathrm{O}_{2}$ consumption and $\mathrm{CO}_{2}$ production were made using a metabolic cart (Beckman Instruments, Inc., Anaheim, CA) (30). The cart was calibrated with standardized gases and a 1,000$\mathrm{ml}$ syringe. Subjects breathed through the mouthpiece with the noseclip in place for 4-5 min to clear the machine of room air. After this equilibration period, respiratory gases were analyzed continuously for 5-6 min with values of $\mathrm{O}_{2}, \mathrm{CO}_{2}$, and ventilation recorded each minute. The specific values reported at each time period for $\mathrm{O}_{2}$ consumption and $\mathrm{CO}_{2}$ production, standardized for temperature, pres- 
Table II. Physical Characteristics, RMR, Plasma Glucose and FFA Concentrations

\begin{tabular}{|c|c|c|c|c|c|c|c|c|c|}
\hline Subject no. & Age & HT & WT & BMI & FFMD & FATMD & RMR & Glucose & FFA \\
\hline & $y r$ & $\mathrm{~cm}$ & $k g$ & $\mathrm{~kg} / \mathrm{m}^{2}$ & $k g$ & $k g$ & $\mathrm{kcal} / \mathrm{min}$ & $m g / d l$ & 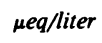 \\
\hline \multicolumn{10}{|c|}{ Lean subjects (BMI <25) } \\
\hline 1 & 29 & 185 & 70.8 & 20.7 & 61.4 & 9.3 & 1.03 & 99 & 240 \\
\hline 2 & 23 & 169 & 65.7 & 23.0 & 57.2 & 8.5 & 0.96 & 88 & 290 \\
\hline 3 & 33 & 181 & 81.0 & 24.7 & 64.6 & 16.4 & 1.04 & 88 & 406 \\
\hline 4 & 22 & 179 & 69.4 & 21.6 & 61.6 & 7.8 & 1.07 & 86 & 509 \\
\hline 5 & 25 & 188 & 79.8 & 22.6 & 67.6 & 12.2 & 1.05 & 88 & 564 \\
\hline Mean & 26 & 180 & 73.3 & 22.5 & 62.5 & 10.8 & 1.03 & 90 & 402 \\
\hline SEM & 2 & 3 & 3.0 & 0.7 & 1.8 & 1.6 & 0.02 & 2 & 62 \\
\hline \multicolumn{10}{|c|}{ Obese subjects (BMI > 30) } \\
\hline 6 & 29 & 166 & 114.2 & 41.2 & 69.8 & 44.4 & 1.22 & 97 & 564 \\
\hline 7 & 24 & 184 & 170.1 & 50.1 & 97.2 & 72.9 & 1.83 & 104 & 389 \\
\hline 8 & 29 & 178 & 130.6 & 41.0 & 88.6 & 42.0 & 1.31 & 92 & 585 \\
\hline 9 & 37 & 175 & 142.0 & 46.2 & 86.0 & 56.0 & 1.72 & 89 & 605 \\
\hline 10 & 34 & 169 & 102.5 & 35.9 & 70.5 & 32.0 & 1.14 & 86 & 334 \\
\hline Mean & 31 & 175 & 131.9 & 42.9 & 82.4 & 49.4 & 1.44 & 93 & 495 \\
\hline SEM & 2 & 3 & 11.7 & 2.4 & 5.3 & 7.0 & 0.14 & 3 & 56 \\
\hline
\end{tabular}

FFMD, fat-free mass by densitometry; FATMD, fat mass by densitometry; glucose, average of preprandial plasma glucose concentrations; FFA, average of preprandial plasma free fatty acid concentrations.

sure, and moisture, represent the means of the five to six 1-min measurements. Urinary nitrogen excretion rates were determined preprandially and $2,4,6$, and $8 \mathrm{~h}$ after nutrient intake, and were used to calculate protein (PRO) oxidation rates (36). Nonprotein $\mathrm{O}_{2}$ consumption, $\mathrm{CO}_{2}$ production, and the nonprotein respiratory quotient were calculated from the formulae described previously (36). Nonprotein calories per liter of $\mathrm{O}_{2}$ and amounts of carbohydrate $(\mathrm{CHO})$ and lipid (FAT) oxidized were derived from the tables of Lusk (36). Oxidation of CHO, FAT, and PRO for the study period was summed by computing the area under separate oxidation curves for $8 \mathrm{~h}$.

Blood samples for measuring plasma glucose (analyzed with a glucose analyzer; Beckman Instruments, Inc.) and plasma urea nitrogen (37) were obtained at -15 and $0 \mathrm{~min}$ before, and at $1 / 2,1,2,3,4,6$, and $8 \mathrm{~h}$ after the test meals. Plasma concentrations of $\alpha$-amino nitrogen (38) and total lipids (39) were measured at 0,4 , and $8 \mathrm{~h}$. Plasma glucose was measured to determine the presence or absence of diabetes mellitus. Plasma urea nitrogen, $\alpha$-amino nitrogen, and total lipids were measured to detect changes in body pools of nitrogen and lipids (40).

Data analysis. The reproducibility of the RMR during the $81 / 4-\mathrm{h}$ study and the RMR variability from day to day were evaluated by computing the mean of the coefficients of variation calculated for each individual's 20 RMR measurements on the zero calorie day, and their five preprandial RMR measurements (30). The TEF was computed as the incremental increase in caloric expenditure over RMR. Three different measurements were used to calculate each man's RMR for computing the TEF: $(a)$ actual values obtained over the 8-h study after the ingestion of water; $(b)$ values obtained each day at -15 - and 0 -min time periods extrapolated over the 8-h study after the ingestion of Ensure Plus; and $(c)$ the average of each subject's -15- and 0-min RMR values from all $5 \mathrm{~d}$ of the study, extrapolated for $8 \mathrm{~h}$ after ingestion of Ensure Plus. The TEF was also expressed as the percentage of caloric intake to standardize the influence of various dietary loads.

Simple regression analysis was used to assess the relationship between TEF and caloric intake, and TEF and WT, BMI, fat-free mass, and fat mass. The possibility of a relationship between TEF, RMR, and resting nonprotein respiratory quotient was also examined. The effect of studying subjects on sequential days was examined by using the numerical study day as a variable in the regression analysis. Stepwise and multiple regression analyses were used to determine which combinations of variables best predicted TEF in the men. The effect of obesity on TEF was determined by using an indicator variable in the regression analyses; that is, a 1 for a BMI $<25$ and a 0 for BMI over 30 (41). Interaction terms were used to assess possible synergistic effects of intake and body compositional variables on TEF.

Intersubject variability of TEF was tested by comparing the thermic response of each individual over the four caloric challenges to the group as a whole. This comparison was made by assigning an indicator variable to each subject and using these in a multiple regression model with intake against TEF. The partial $F$ test was used to compare this multiple regression model with the regression of TEF against intake alone (41). The inclusion of subject effects in the multiple regression analyses insured that the errors were independent, as is required for hypothesis testing.

The time course of TEF was assessed using measures of the duration of augmented postprandial energy expenditure and the time from feeding to peak caloric expenditure. The duration of TEF was the interval from time 0 to the time of return of energy expenditure to preprandial values. In determining when subjects' postprandial energy expenditures returned to preprandial values, we used a range above the baseline RMR value to account for measurement variability. The range for each subject was based on either the SD of that subject's RMR measurements on the zero calorie day, or the SD of all the subjects' (group SD) RMR measurements on the zero calorie day. We used three definitions of the return of energy expenditure to baseline in estimating the duration of TEF: $(a)$ one postpeak energy expenditure measurement within two-group SD of preprandial baseline; $(b)$ two consecutive postpeak energy expenditure measurements within twogroup SD of preprandial baseline; and (c) two consecutive postpeak energy expenditure measurements within two of the individuals' SD of preprandial baseline. The duration of TEF and the time to postpran- 
Table III. Caloric Intake and Related Thermic Effect of Food

\begin{tabular}{|c|c|c|c|c|c|c|c|c|c|c|c|}
\hline \multirow{2}{*}{$\begin{array}{c}\text { Subject } \\
\text { no. }\end{array}$} & \multicolumn{2}{|c|}{ Intake } & \multirow[b]{2}{*}{ RMR } & \multirow[b]{2}{*}{ TEF } & \multirow[b]{2}{*}{ TEF/intake } & \multirow{2}{*}{$\begin{array}{c}\text { Subject } \\
\text { no. }\end{array}$} & \multicolumn{2}{|c|}{ Intake } & \multirow[b]{2}{*}{ RMR } & \multirow[b]{2}{*}{ TEF } & \multirow[b]{2}{*}{ TEF/intake } \\
\hline & kg FFMD & Total & & & & & kg FFMD & Total & & & \\
\hline & \multicolumn{2}{|c|}{ kcal } & $\mathrm{kcal} / 8 \mathrm{~h}$ & $k c a l$ & \% intake & & $k c$ & & $\mathrm{kcal} / 8 \mathrm{~h}$ & kcal & \% intake \\
\hline \multicolumn{6}{|c|}{ Lean subjects (BMI <25) } & \multicolumn{6}{|c|}{ Obese subjects $(\mathrm{BMI}>30)$} \\
\hline 1 & 8 & 491 & 495 & 35.5 & 7.2 & 6 & 8 & 558 & 585 & 37.4 & 6.7 \\
\hline 2 & 8 & 458 & 461 & 2.2 & 0.5 & 7 & 8 & 776 & 879 & 66.9 & 8.6 \\
\hline 3 & 8 & 513 & 498 & 6.3 & 1.2 & 8 & 8 & 715 & 628 & 84.7 & 11.8 \\
\hline 4 & 8 & 493 & 514 & 41.1 & 8.3 & 9 & 8 & 688 & 824 & 16.2 & 2.4 \\
\hline 5 & 8 & 540 & 505 & 84.1 & 15.6 & 10 & 8 & 563 & 692 & 12.6 & 2.2 \\
\hline Mean & & 499 & 495 & 33.8 & 6.6 & Mean & & 660 & 722 & 43.6 & 6.3 \\
\hline SEM & & 14 & 9 & 14.7 & 2.7 & SEM & & 43 & 56 & 14.1 & 1.8 \\
\hline 1 & 16 & 982 & 495 & 123.0 & 12.5 & 6 & 16 & 1,117 & 585 & 153.3 & 13.7 \\
\hline 2 & 16 & 916 & 461 & 94.3 & 10.3 & 7 & 16 & 1,552 & 879 & 134.8 & 8.7 \\
\hline 3 & 15 & 998 & 498 & 82.6 & 8.3 & 8 & 16 & 1,429 & 628 & 115.3 & 8.1 \\
\hline 4 & 16 & 985 & 514 & 59.5 & 6.0 & 9 & 16 & 1,374 & 824 & 69.4 & 5.0 \\
\hline 5 & 16 & 1,081 & 505 & 90.4 & 8.4 & 10 & 16 & 1,128 & 692 & 71.0 & 6.3 \\
\hline Mean & & 992 & 495 & 90.0 & 9.1 & Mean & & 1,320 & 722 & 108.8 & 8.4 \\
\hline SEM & & 26 & 9 & 10.2 & 1.1 & SEM & & 86 & 56 & 16.8 & 1.5 \\
\hline 1 & 24 & 1,471 & 495 & 143.2 & 9.7 & 6 & 24 & 1,675 & 585 & 144.0 & 8.6 \\
\hline 2 & 24 & 1,376 & 461 & 127.5 & 9.3 & 7 & 24 & 2,321 & 879 & 229.2 & 9.9 \\
\hline 3 & 24 & 1,540 & 498 & 138.8 & 9.0 & 8 & 24 & 2,146 & 628 & 157.4 & 7.3 \\
\hline 4 & 24 & 1,475 & 514 & 104.0 & 7.0 & 9 & 24 & 2,063 & 824 & 122.2 & 5.9 \\
\hline 5 & 23 & 1,580 & 505 & 126.8 & 8.0 & 10 & 24 & 1,691 & 692 & 138.8 & 8.2 \\
\hline Mean & & 1,488 & 495 & 128.0 & 8.6 & Mean & & 1,979 & 722 & 158.3 & 8.0 \\
\hline SEM & & 35 & 9 & 6.8 & 0.5 & SEM & & 128 & 56 & 18.6 & 0.7 \\
\hline 1 & 32 & 1,962 & 495 & 189.0 & 9.6 & 6 & 32 & 2,232 & 585 & 203.8 & 9.1 \\
\hline 2 & 32 & 1,835 & 461 & 115.4 & 6.3 & 7 & 32 & 3,104 & 879 & 234.9 & 7.6 \\
\hline 3 & 31 & 1,996 & 498 & 152.7 & 7.6 & 8 & 28 & 2,438 & 628 & 193.0 & 7.9 \\
\hline 4 & 27 & 1,677 & 514 & 132.0 & 7.9 & 9 & 32 & 2,749 & 824 & 195.2 & 7.1 \\
\hline 5 & 28 & 1,870 & 505 & 197.3 & 10.6 & 10 & 32 & 2,255 & 692 & 196.0 & 8.7 \\
\hline Mean & & 1,868 & 495 & 157.3 & 8.4 & Mean & & 2,556 & 722 & 204.6 & 8.1 \\
\hline SEM & & 56 & 9 & 15.8 & 0.8 & SEM & & 165 & 56 & 7.8 & 0.4 \\
\hline
\end{tabular}

dial peak energy expenditure were analyzed by simple and stepwise regression analysis for relationships to intake, WT, BMI, fat-free mass, and RMR.

Resistant regression lines (Minitab Statistical Package, Version 82.1.1; Minitab, Inc., Penn State University, State College, PA) (42) and three-dimensional response surfaces were used to display the relationship among time, caloric intake, and TEF.

\section{Results}

Body composition, caloric intake, and indirect calorimetry. The obese men had significantly greater WT, BMI, fat-free mass, fat mass, and RMR than the lean subjects $(P<0.025$ for all values), and no member of either group had parameters of body size that were similar to those of the other group (Table II).

The RMR during the $81 / 4-\mathrm{h}$ control day when the subjects drank $500 \mathrm{ml}$ of water were very reproducible, and the random variance was $<4 \%$ of the mean, which was similar to previous results in this (30) and other laboratories (16). The day to day variability of RMR was also small with a coefficient of variation of $4 \%$. In addition, the $-15-$ and $0-$ min RMR measure- ments over the 5-d study were not statistically different. The TEF values, regardless of which one of the three different RMR measurements was used, also were not statistically different. We used the RMR measured before each meal to calculate the subsequent TEF.

The caloric content of the meals (Ensure Plus) based on the subjects' fat-free mass, ranged from 458 to $3,104 \mathrm{kcal}$. The caloric intakes and postprandial TEF for the lean and obese groups at the four meal sizes are shown in Table III. All subjects were in positive energy balance during the 8-h postprandial period after the $16-, 24-$, and $32-\mathrm{kcal} / \mathrm{kg}$ fat-free mass meals. However, after consuming the lowest caloric load, 8 $\mathrm{kcal} / \mathrm{kg}$ fat-free mass, three lean and four obese subjects $(1,2$, $3,6,7,8$, and 9) received less than their resting requirements for the 8-h postprandial period.

The postprandial RMR did not fully return to baseline in several of our subjects after their highest caloric challenges. However, after $8 \mathrm{~h}$ these men were near baseline energy expenditure. Furthermore, when we excluded them from analyses, the relationships of TEF to other variables were not significantly altered. Thus, in a practical sense, TEF was completely measured. 


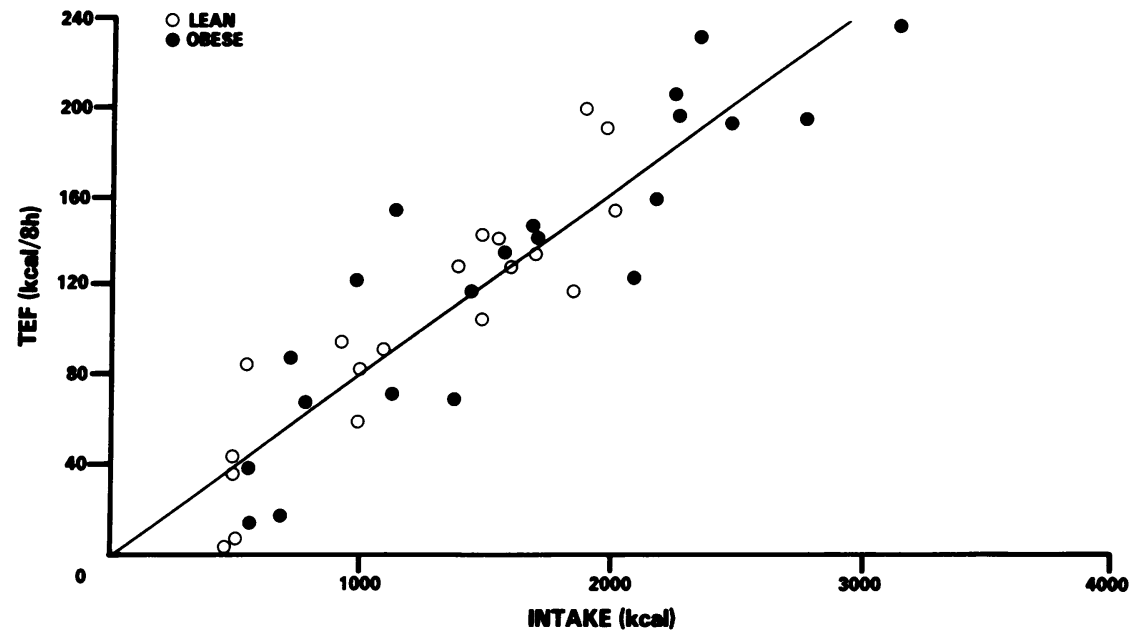

Figure 1. Thermic effect of mixed meals in 10 healthy males. The four caloric challenges fed to each of five lean $(0)$ and five obese $(\bullet)$ men are plotted against their corresponding TEF. The regression line $(\mathrm{TEF}=-1.16+0.082$ kcal intake) for the relationship between TEF and caloric intake is shown.
Thermic effect of food. Fig. 1 shows that TEF was positively correlated with caloric intake $(P<0.001)$. The relationships between TEF and caloric intake were not statistically different for lean and obese men. Therefore, a single regression line was developed. TEF can be predicted by the following equation: TEF $=-1.16+0.082 \mathrm{kcal}$ intake $\left(r^{2}=0.82\right)$. Although TEF expressed as a percent of intake (TEF/intake) was variable in both groups, the average values for different diets, and for lean and obese subjects, were not statistically different. Irrespective of nutrient intake, the mean TEF was $\sim 8 \%$ of the ingested calories (Table III).

TEF was not correlated with WT, fat-free mass, or fat mass. The mean TEF values plotted against the mean caloric intakes at the 8-, 16-, 24-, and 32-kcal/kg fat-free mass diets for lean and obese subjects are shown in Fig. 2. The linear relationship for lean and obese men shows that TEF was not influenced by obesity. On the other hand, each of the 10 men had individually consistent thermic responses to the Ensure Plus meals. Fig. 3 shows the actual and the predicted TEF for each subject

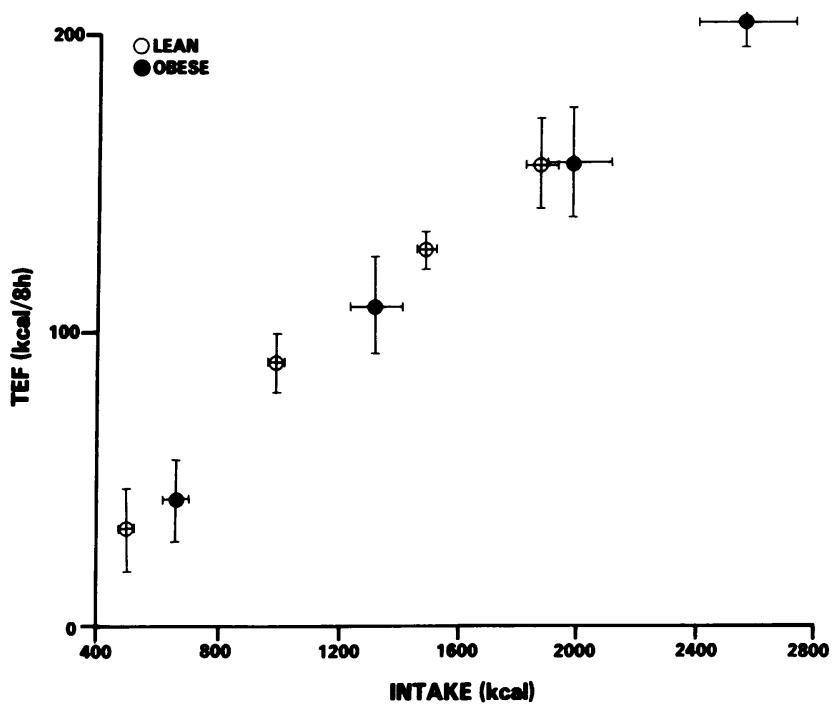

Figure 2. Average caloric intakes given to lean ( 0 ) and obese $(\bullet)$ men for the $8,16,24$, and $32 \mathrm{kcal} / \mathrm{kg}$ fat-free mass mixed meal challenges and corresponding TEF. across the range of caloric challenges. Several subjects had responses that were shifted above or below the group average, and the overall variation was statistically significant $(F=4.18$, $P<0.01$ ). Thus, the subjects had individually distinct thermic responses to a given caloric challenge. This intersubject variation was independent of leanness or obesity.

Fig. 4 shows a three-dimensional response surface generated from resistant regression lines relating caloric intake to energy expenditure at each postprandial time. The magnitude and duration of the augmented thermogenesis over preprandial RMR increased linearly with the caloric intake. With the largest caloric challenges the RMR was increased by $\sim 30 \%$. The duration of TEF was highly correlated with caloric intake regardless of the model used for calculating time of postprandial thermogenesis. Subjects with higher preprandial energy expenditures had a shorter duration of TEF for a given caloric intake. The time from meal ingestion to peak thermogenesis was also significantly related to intake $(r=0.41 ; P<0.025)$ with a secondary negative relationship to $\operatorname{RMR}(P<0.01)$.

Postprandial metabolism. No subject had plasma glucose values diagnostic of diabetes mellitus (43). The preprandial plasma urea nitrogen concentrations were indistinguishable between lean and obese males, and in both groups, the 8-h postprandial plasma urea nitrogen concentrations were indistinguishable from the preprandial values. Total plasma lipid concentrations were greater than preprandial values only in the obese males after the largest caloric challenge.

\section{Discussion}

This study is a systematic reappraisal of the thermic effect of food after multiple caloric challenges of mixed meals in lean and obese humans. Only males were studied to eliminate the known influence of gender on postprandial metabolism (44). Our volunteers were fed a range of caloric challenges simulating intakes from a small meal to the equivalent of a full day's consumption. The results showed that TEF was dictated primarily by caloric intake, and this relationship was constant across all the dietary intakes studied (Fig. 1). Throughout this range of caloric challenges TEF increased with greater caloric intakes in a linear fashion. There was no evidence that thermogenesis became either accentuated or blunted by high caloric intake (Fig. 2). 

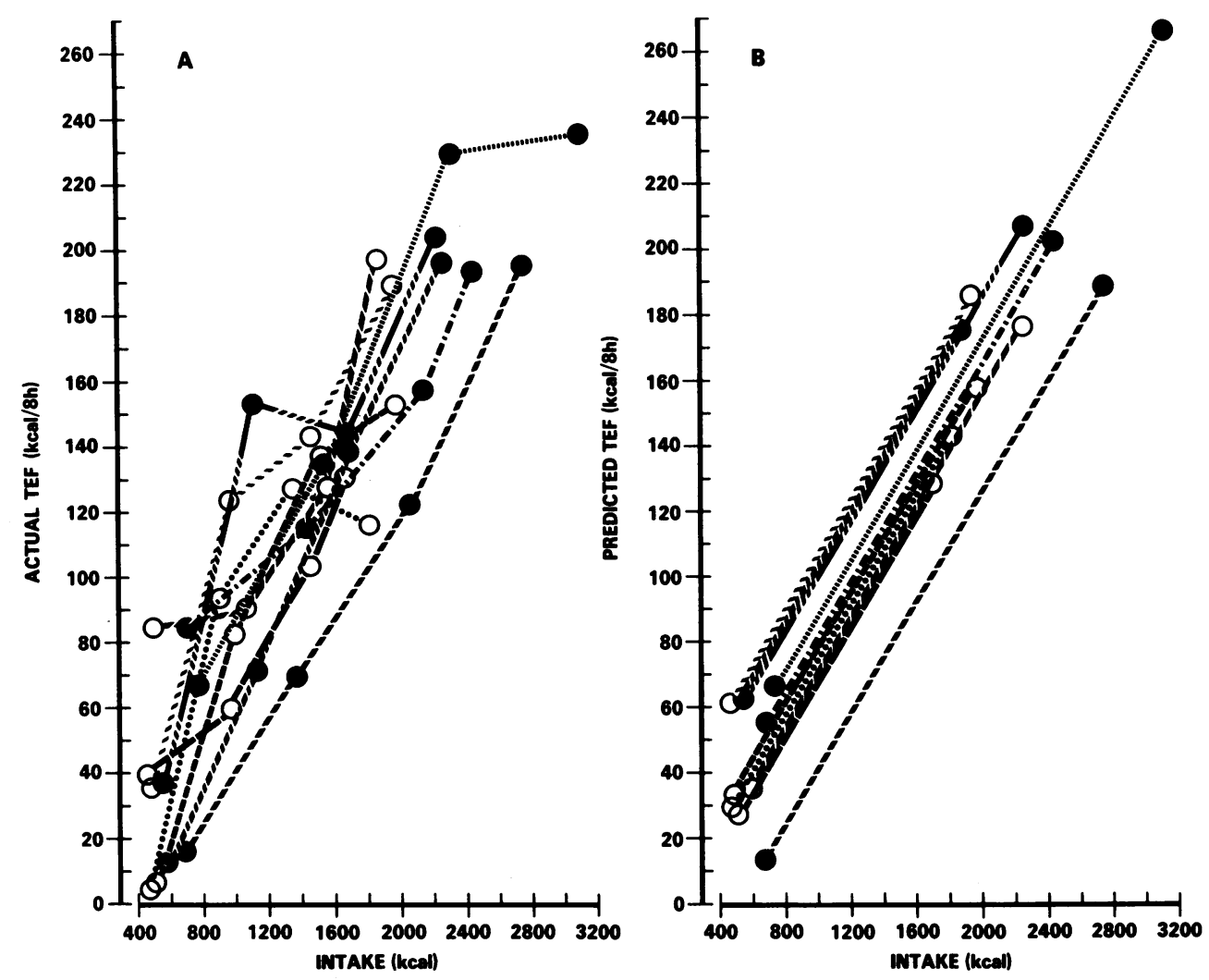

Figure 3. (A) Actual individual thermic responses to mixed meals in five lean (0) and five obese (๑) men are shown. The slopes of these lines are similar, but there are statistically significant differences among the intercepts. ( $B$ ) Predicted individual thermic responses to progressively greater caloric challenges were plotted using each subject's intercept. The intercepts were derived from a multiple regression model using indicator variables. The group regression line for TEF and intake was used for each man in the range of calories he ingested.

One of the novel findings of this study was the consistent and distinct TEF of individuals. By feeding the subjects a variety of dietary challenges the specific response of a person to mixed meals was demonstrated (Fig. 3). The increase in energy expenditure per caloric intake was relatively constant for an individual and generally distinguishable from another man. The TEF of an individual was independent of body size or composition. Variations in metabolic efficiency during the fasting and resting states are independent of WT $(30,33)$ and

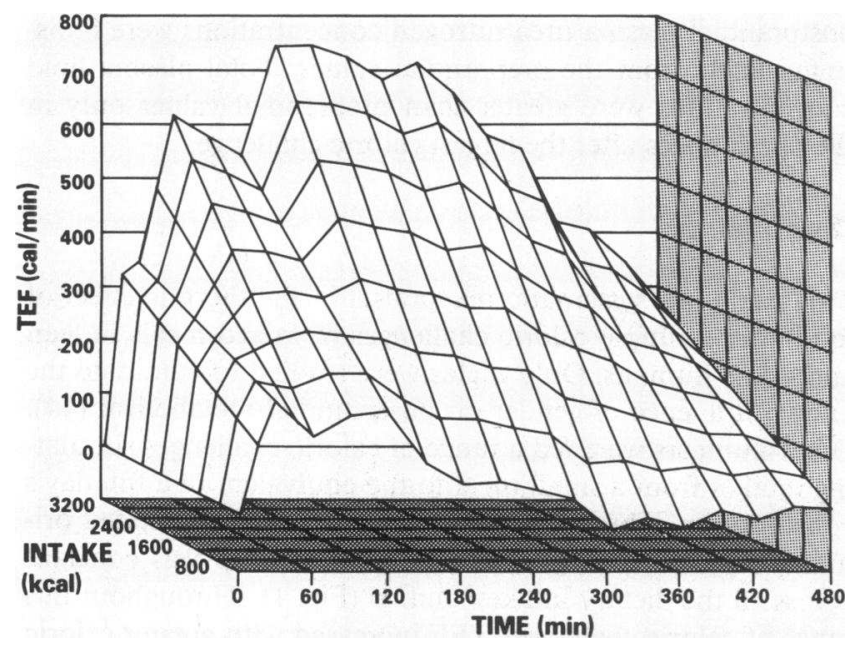

Figure 4. Three-dimensional response surface, generated from resistant regression lines, relating caloric intake to the thermic effects of food during the 8-h study period. this report suggests that humans have unique metabolic responses to food which are also independent of leanness and obesity. This metabolic individuality is functionally equivalent to a "metabolic fingerprint." This individualistic thermic profile to food plays an important role in energy balance. The lack of consensus pertaining to TEF in obesity (6-32) may have resulted from selecting more or fewer individuals with high postprandial thermogenesis in either the lean or obese group.

There was no statistically significant correlation between TEF and body size in our study. Unlike RMR, which is correlated to the active protoplasmic tissue mass $(30,33)$, TEF was independent of WT, fat-free mass, fat mass, and BMI. We gave

Table IV. Diet, Intake, RMR, and Energy Expenditure in Three Lean and Three Obese Men Fed Similar Caloric Challenges

\begin{tabular}{|c|c|c|c|c|c|}
\hline $\begin{array}{c}\text { Subject } \\
\text { no. }\end{array}$ & Diet & Intake & RMR & TEF & EE \\
\hline & kcal/kg FFMD & kcal & $\mathrm{kcal} / 8 \mathrm{~h}$ & $\mathrm{kcal} / 8 \mathrm{~h}$ & $\mathrm{kcal} / 8 \mathrm{~h}$ \\
\hline \multicolumn{6}{|c|}{ Lean subjects (BMI <25) } \\
\hline 3 & 24 & 1,541 & 466 & 139 & 605 \\
\hline 5 & 24 & 1,581 & 517 & 127 & 644 \\
\hline 4 & 32 & 1,677 & 503 & 132 & 635 \\
\hline \multicolumn{6}{|c|}{ Obese subjects (BMI $>30$ ) } \\
\hline 7 & 16 & 1,522 & 835 & 135 & 970 \\
\hline 6 & 24 & 1,674 & 595 & 144 & 739 \\
\hline 10 & 24 & 1,691 & 545 & 139 & 684 \\
\hline
\end{tabular}




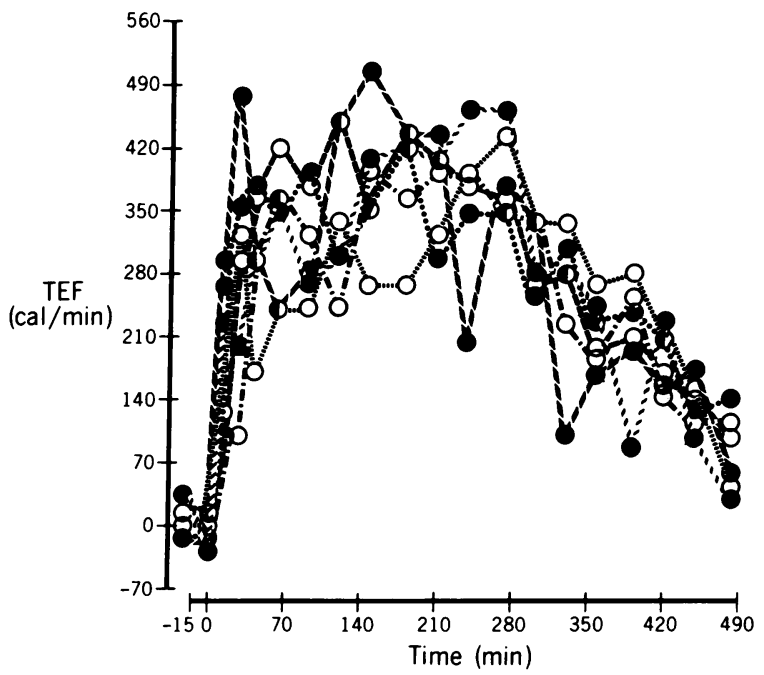

Figure 5. Thermic responses to similar caloric intakes in three lean $(0)$ and three obese $(\bullet)$ men.

our subjects caloric challenges based on fat-free mass because it was previously suggested that caloric intake above resting needs determines TEF (31). We cannot support this contention because our data show that caloric intake per se determines TEF. Table IV shows data from three lean and three obese men who were incidentally fed similar amounts of Ensure Plus (coefficient of variation for caloric intake was $4.8 \%$ ). Fig. 5 shows their energy response curves to these comparable caloric challenges. The TEF among these three lean and three obese males were virtually identical (coefficient of variation for TEF was 4.4\%). Equal augmentation of postprandial energy expenditure occurred in spite of the obviously greater RMR and total energy expenditures in the three obese men. This clearly illustrates that TEF is independent of leanness and obesity.

The time course of TEF was also primarily a function of caloric intake. We confirmed the previous observation that the duration of TEF is lengthened as caloric intake increases (45, 46). This general observation can be further characterized by using the results from selected individuals fed similar caloric intakes. From the 10 men studied 6 could be identified who received four different meals containing 490-563, 981-1,127, $1,374-1,552$, and $1,962-2,255 \mathrm{kcal}$. Using a resistant regression model their TEF are displayed in Fig. 6. The magnitude of the TEF was greater and the duration of the TEF was lengthened as the caloric intake increased.

The duration of postprandial energy expenditure measurement is a major factor which accounts for some of the claimed deficiency of TEF in obesity. Many of the previous studies measuring TEF in lean and obese individuals were too short to make an adequate assessment of postprandial thermogenesis $(8,11,13,16,19-20,26,29,30)$. Whereas incomplete measurement of TEF does not lead to a clear bias for or against a thermic defect in the obese, conclusions based on partial results are indefinite. Previous studies of an individual's responses to several caloric loads showed a diminished TEF rise with larger intakes. Both Hill et al. (46) and Belko et al. (47) fed normal subjects meals containing $\sim 500,1,000$, and 1,500 $\mathrm{kcal}$. They found linear and negative quadratic components to

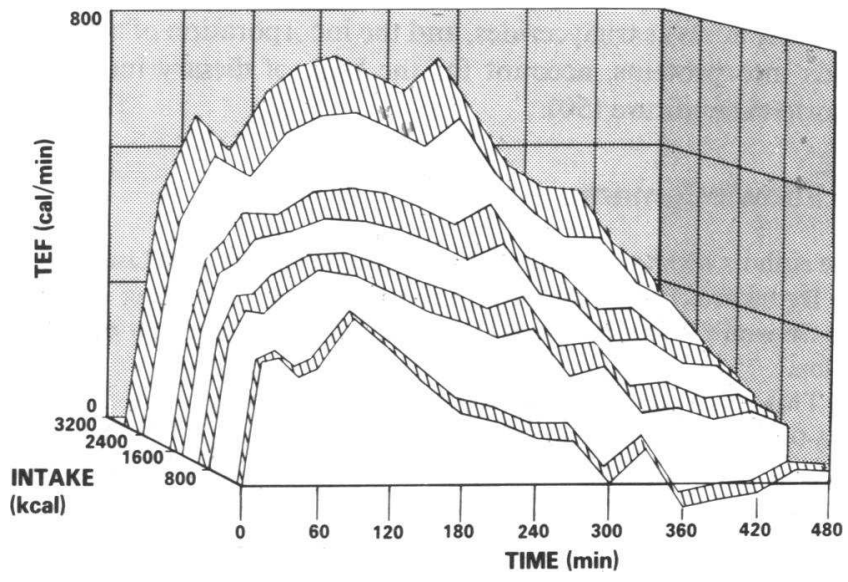

Figure 6. A three-dimensional surface displaying the TEF in three lean and three obese individuals who ingested four different caloric challenges (490-563, 981-1,127, 1,374-1,552, and 1,962-2,255 kcal) containing $43 \% \mathrm{CHO}, 42 \% \mathrm{FAT}$, and $15 \%$ PRO.

their relationships between TEF and caloric intake. However, in both of these reports the TEF with the higher diets was underestimated because the studies were concluded long before postprandial energy expenditure returned to baseline. The TEF in our study did not plateau with larger caloric intakes because we studied our subjects for $8 \mathrm{~h}$ and did not significantly underestimate TEF.

Different degrees of glucose intolerance within groups of obese subjects may account for some of the disagreement regarding obesity and TEF. Felber et al. (21) showed variation in TEF that was related to the degree of glucose intolerance in healthy and diabetic men and women. Our lean and obese men had physiologic blood glucose concentrations in response to the varying caloric challenges. Therefore, the influence of glucose intolerance was eliminated in our study. In addition, our 8-h study period was sufficiently long enough for plasma total lipids, $\alpha$-amino nitrogen, and urea nitrogen to return to preprandial values. Therefore, changes in the pool sizes of these substrates and/or metabolites had no significant impact on calculated postprandial energy expenditure.

Exceptional physical characteristics in lean controls may also be a source of disagreement in previous TEF studies. For example, Segal et al. (19) studied a group of lean men matched with obese subjects for height and weight. Their lean controls, however, were athletes in training with very large muscle masses and higher RMR and TEF than their obese subjects. Hill et al. (46) showed that aerobically trained men have greater TEF than men with lower maximal oxygen consumptions. The inclusion of individuals with exceptional thermogenic capacities as controls creates an apparent attenuation in the TEF of their obese cohorts. This bias is especially important with the small number of subjects that have been compared in past studies of TEF.

It was shown by others that TEF is similar whether nutrients are administered orally, intravenously, or via nasogastric tube $(32,48,49)$. This demonstrated that the caloric requirements of mastication, swallowing, and intestinal absorption are minimal. Therefore, it is likely that the ATP and other nucleotide requirements for the storage of glucose as glycogen, 
free fatty acids as triglycerides, and the incorporation of amino acids into proteins, account for the bulk of dietary induced caloric expenditure (50).

\section{Acknowledgments}

The authors wish to thank Tom Young, Brenda Blyler, and Lisa Panting for their technical assistance, Isabel Ryan and the nursing staff of the General Clinical Research Center, and Dr. Luc Tappy for consultation.

This work was supported in part by training grant 5 T32 AM-07162-09, U. S. Public Health Services grant RR-00349, General Clinical Research Centers Branch, National Institutes of Health, the Upjohn Company, and Wilkie Buick/GMC Truck/Subaru.

\section{References}

1. Van Italie, T. B. 1985. Health implications of overweight and obesity in the United States. Ann. Intern. Med. 103:983-988.

2. Bjorntorp, P. 1985. Regional patterns of fat distribution. Ann. Intern. Med. 106(Suppl. 2):994-995.

3. Hubert, H. B., M. Feinleib, P. M. McNamara, and W. P. Castelli. 1983. Obesity as an independent risk factor for cardiovascular disease: a 26-year follow-up of participants in the Framingham Heart Study. Circulation. 67:968-977.

4. Barrett-Connor, E. L. 1985. Obesity, atherosclerosis, and coronary artery disease. Ann. Intern. Med. 103:1010-1019.

5. Kral, J. G. 1985. Morbid obesity and related health risks. Ann. Intern. Med. 103:1043-1047.

6. Pittet, P., P. Chappuis, K. Acheson, F. de Techtermann, and E. Jequier. 1976. Thermic effect of glucose in obese subjects studied by direct and indirect calorimetry. Br. J. Nutr. 35:281-292.

7. Kaplan, M. L., and G. A. Leveille. 1976. Calorigenic response in obese and nonobese women. Am. J. Clin. Nutr. 29:1108-1113.

8. Shetty, P. S., R. T. Jung, W. P. T. James, M. A. Barrand, and B. A. Callingham. 1981. Postprandial thermogenesis in obesity. Clin. Sci. 60:519-525.

9. Zed, C. A., and W. P. T. James. 1982. Thermic response to fat feeding in lean and obese subjects. Proc. Nutr. Soc. 41:32a. (Abstr.)

10. Golay, A., Y. Schutz, H. U. Meyer, D. Thiebaud, B. Curchod, E. Maeder, J.-P. Felber, and E. Jequier. 1982. Glucose-induced thermogenesis in nondiabetic and diabetic obese subjects. Diabetes. 31:1023-1028.

11. Swaminathan, R., R. F. J. King, J. Holmfield, and J. K. Wales. 1982. Dietary fat induced thermogenesis in obesity. Clin. Sci. (Lond.). 62:16p. (Abstr.)

12. Schwartz, R. S., J. B. Halter, and E. L. Bierman. 1983. Reduced thermic effect of feeding in obesity: role of norepinephrine. Metab. Clin. Exp. 32:114-117.

13. Bessard, T., Y. Schutz, and E. Jequier. 1983. Energy expenditure and postprandial thermogenesis in obese women before and after weight loss. Am. J. Clin. Nutr. 38:680-693.

14. Schutz, Y., T. Bessard, and E. Jequier. 1984. Diet-induced thermogenesis measured over a whole day in obese and nonobese women. Am. J. Clin. Nutr. 40:542-552.

15. Ravussin, E., C. Bogardus, R. S. Schwartz, D. C. Robbins, R. R. Wolfe, E. S. Horton, E. Danforth, Jr., and E. A. H. Sims. 1983. Thermic effect of infused glucose and insulin in man. J. Clin. Invest. 72:893-902.

16. Segal, K. R., E. Presta, and B. Gutin. 1984. Thermic effect of food during graded exercise in normal weight and obese men. Am. J. Clin. Nutr. 40:995-1000.

17. Schutz, Y., A. Golay, J.-P. Felber, and E. Jequier. 1984. Decreased glucose-induced thermogenesis after weight loss in obese subjects: a predisposing factor for relapse of obesity? Am. J. Clin. Nutr. 39:380-387.

18. Bogardus, C., S. Lillioja, D. Mott, J. Zawadzki, A. Young, and
W. Abbott. 1985. Evidence for reduced thermic effect of insulin and glucose infusions in Pima Indians. J. Clin. Invest. 75:1264-1269.

19. Segal, K. R., B. Gutin, A. M. Nyman, and F. X. Pi-Sunyer. 1985. Thermic effect of food at rest, during exercise, and after exercise in lean and obese men of similar body weight. J. Clin. Invest. 76:1107-1112.

20. Segal, K. R., B. Gutin, J. Albu, and F. X. Pi-Sunyer. 1987. Thermic effects of food and exercise in lean and obese men of similar lean body mass. Am. J. Physiol. 252:E110-E117.

21. Felber, J.-P., H. U. Meyer, B. Curchod, H. U. Iselin, J. Rousselle, E. Maeder, P. Pahud, and E. Jequier. 1981. Glucose storage and oxidation in different degrees of human obesity measured by continuous indirect calorimetry. Diabetologia. 20:39-44.

22. Sharief, N. N., and I. Macdonald. 1982. Differences in dietaryinduced thermogenesis with various carbohydrates in normal and overweight men. Am. J. Clin. Nutr. 35:267-272.

23. Welle, S. L., and R. G. Campbell. 1983. Normal thermic effect of glucose in obese women. Am. J. Clin. Nutr. 37:87-92.

24. Nair, K. S., D. Halliday, and J. S. Garrow. 1983. Thermic response to isoenergetic protein, carbohydrate or fat meals in lean and obese subjects. Clin. Sci. (Lond.). 65:307-312.

25. Blaza, S., and J. S. Garrow. 1983. Thermogenic response to temperature, exercise and food stimuli in lean and obese women, studied by 24 h direct calorimetry. Br. J. Nutr. 49:171-180.

26. Felig, P., J. Cunningham, M. Levitt, R. Hendler, and E. Nadel. 1983. Energy expenditure in obesity in fasting and postprandial state. Am. J. Physiol. 244:E45-E51.

27. Schwartz, R. S., E. Ravussin, M. Massari, M. O'Connell, and D. C. Robbins. 1985. The thermic effect of carbohydrate versus fat feeding in man. Metab. Clin. Exp. 34:285-293.

28. Ravussin, E., K. J. Acheson, O. Vernet, E. Danforth, and E. Jequier. 1985. Evidence that insulin resistance is responsible for the decreased thermic effect of glucose in human obesity. J. Clin. Invest. 76:1268-1273.

29. Swaminathan, R., R. F. G. J. King, J. Holmfield, R. A. Siwek, M. Baker, and J. K. Wales. 1985. Thermic effect of feeding carbohydrate, fat, protein and mixed meals in lean and obese subjects. Am. J. Clin. Nutr. 42:177-181.

30. Owen, O. E., E. Kavle, R. S. Owen, M. Polansky, S. Caprio, M. Mozzoli, Z. V. Kendrick, M. C. Bushman, and G. Boden. 1986. A reappraisal of caloric requirements in healthy women. Am. J. Clin. Nutr. 44:1-9.

31. Nair, K. S., J. Webster, and J. S. Garrow. 1986. Effect of impaired glucose tolerance and type II diabetes on resting metabolic rate and thermic response to a glucose meal in obese women. Metab. Clin. Exp. 35:640-644.

32. Vernet, O., L. Christin, Y. Schutz, E. Danforth, Jr., and E. Jequier. 1986. Enteral versus parenteral nutrition: comparison of energy metabolism in lean and moderately obese women. Am. J. Clin. Nutr. 43:194-209.

33. Owen, O. E., J. L. Holup, D. A. D'Alessio, E. S. Craig, M. Polansky, K. J. Smalley, E. C. Kavle, M. C. Bushman, L. R. Owen, M. A. Mozzoli, Z. V. Kendrick, and G. H. Boden. 1987. A reappraisal of the caloric requirements of men. Am. J. Clin. Nutr. 46:875-885.

34. Bray, G. A. 1984. Obesity: benefits and risks of treatment. Drug Therapy. 14:60-65.

35. Cochran, W. G., and D. R. Cox. 1957. Experimental Designs. 2nd ed. John Wiley and Sons, New York. 117-127.

36. Best, C., and W. B. Taylor. 1961. The Physiological Basis of Medical Practice. 7th ed. Williams and Wilkins, Baltimore, MD. 741-768.

37. Marsh, W. H., B. Fingerhut, and H. Miller. 1965. Automated and manual direct methods for the determination of blood urea. Clin. Chem. 11:624-627.

38. Kekki, M. 1959. Microdetermination of amino nitrogen as copper complexes: a modification for plasma and urine. Scand.J. Clin. Lab. Invest. 11:311-321.

39. Folch, J., M. Lees, and G. H. Stanley. 1956. A simple method 
for the isolation of total lipids from animal tissues. J. Biochem. (Tokyo). 226:497-509.

40. Tappy, L., O. E. Owen, and G. Boden. 1988. Effect of hyperinsulinemia on urea-pool size and substrate oxidation rates. Diabetes. In press.

41. Kleinbaum, D. G., and L. L. Krupper. 1978. Applied Regression Analysis and Other Multivariable Methods. Duxbury Press, Boston, MA. 188-195.

42. Mosteller, F., and J. W. Tukey. 1977. Data Analysis and Regression. Addison-Wesley Publishing Co., Reading, MA. 203-218.

43. National Diabetes Group. 1979. Classification and diagnosis of diabetes mellitus and other categories of glucose intolerance. Diabetes. 28:1039-1057.

44. Owen, O. E., M. A. Mozzoli, G. Boden, M. S. Patel, G. A. Reichard, Jr., V. Trapp, C. R. Shuman, and P. Felig. 1980. Substrate, hormone, and temperature responses in males and females to a common breakfast. Metab. Clin. Exp. 29:511-523.

45. Miller, D. S., P. Mumford, and M. J. Stock. 1967. Gluttony. 2.
Thermogenesis in overeating man. Am. J. Clin. Nutr. 20:1223-1229.

46. Hill, J. O., S. B. Heymsfield, C. McMannus III, and M. DiGirolamo. 1984. Meal size and thermic response to food in male subjects as a function of maximum aerobic capacity. Metab. Clin. Exp. 33:743-749.

47. Belko, A. Z., T. F. Barbieri, and E. C. Wong. 1986. Effect of energy and protein intake and exercise intensity on the thermic effect of food. Am. J. Clin. Nutr. 43:863-869.

48. Vernet, O., L. Christin, Y. Schutz, E. Danforth, Jr., and E. Jequier. 1986. Enteral versus parenteral nutrition: comparison of energy metabolism in healthy subjects. Am. J. Physiol. 250:E47-E54.

49. Hill, J. O., M. DiGirolamo, and S. B. Heymsfield. 1985. Thermic effect of food ingested versus tube-delivered meals. Am. J. Physiol. 248:E370-E374.

50. Flatt, J. P. 1978. The biochemistry of energy expenditure. In Obesity Research II. G. A. Bray, editor. Newman Publishing Inc., London. 211-228. 